\title{
Shape Factor Effect on Inclusion Sedimentation in Aluminum Melts
}

\author{
MERTOL GÖKELMA, KRISTIAN ETIENNE EINARSRUD, GABRIELLA TRANELL, \\ and BERND FRIEDRICH
}

The quality requirements of aluminum products are steadily increasing, and the presence of non-metallic inclusions have a large impact on the quality of aluminum products. Sedimentation is a widely applied technique to remove inclusions and the settling characteristic of particles is one of the most important parameters determining the removal efficiency. The settling characteristics can be modeled analytically through different approaches. A comparison of settling according to the Stokes and Schiller and Naumann drag force formulations was investigated and showed that Stokes drag is relevant for inclusions in aluminum melts. The settling of particles is analytically and experimentally investigated in this study by using a shape factor " $K$ " based on Stokes law and online particle tracking by LiMCA (Liquid Metal Cleanliness Analyzer), respectively. The effect of the shape factor on settling velocities was observed clearly and the measured data show considerably slower settling than traditional models, indicating the effect of melt flow due to thermal convection.

https://doi.org/10.1007/s11663-020-01769-0

(C) The Author(s) 2020

\section{INTRODUCTION}

THE quality requirements of flat aluminum products increase consistently. The quality of the products with low wall thicknesses, such as foils and lithography sheets, strongly depends on the concentration of remaining non-metallic inclusions after the melt treatment steps. ${ }^{[1-3]}$ Non-metallic inclusions are removed mainly by flotation, sedimentation, and filtration. Sedimentation is a removal mechanism benefiting from the density difference between the melt and the inclusions. Particles will tend to settle in case of a higher density than the melt, ${ }^{[4]}$ however, the settling velocity will be also affected by the morphology of the particle.

Stokes's law is typically used for particle settling calculations in fluids. ${ }^{5]}$ The settling rate equations are derived by assuming that particles are perfect spheres, which is not the case in practice. Leith investigated a dynamic shape factor $K$, based on Stokes law for

MERTOL GÖKELMA, KRISTIAN ETIENNE EINARSRUD, and GABRIELLA TRANELL are with the Department of Materials Science and Engineering, Norwegian University of Science and Technology, Trondheim, 7491, Norway. Contact e-mail: mertol.gokelma@ntnu.no BERND FRIEDRICH is with the IME Process Metallurgy and Metal Recycling, RWTH Aachen University, Aachen, 52056, Germany.

Manuscript submitted August 3, 2019.

Article published online January 22, 2020. non-spherical particles. This extension uses the equivalent spherical diameters " $d_{\mathrm{eq}}$ " to define the drag force acting on a non-spherical particle. ${ }^{[6]}$

Different analytical and experimental approaches have been introduced for the settling of non-spherical particles in the literature. Dietrich proposed a settling model using Corey's Shape Factor (CSF), nominal diameter, and roundness. ${ }^{[7]}$ Hartman et al. experimentally measured the settling velocity of lime $(\Psi=0.78)$ and limestone $(\Psi=0.55)$ particles over $0.1 \mathrm{~mm}$ in dried air as a medium. ${ }^{[8]}$ Tsakalakis et al. measured the settling velocity of irregularly shaped galena and quartz particles over $0.1 \mathrm{~mm}$ in water. ${ }^{[9]}$ Tran-Cong et al. measured the settling of agglomerates having six different geometries from smooth glass spheres in water-glycerin solutions. An extension to Schiller and Naumann drag law for irregular shapes and moderate Reynolds numbers is also presented. ${ }^{[10]}$ Simensen analyzed sedimentation of inclusions in aluminum by use of light microscopy after solidification of samples under centrifugation. ${ }^{[11]}$ Razaz studied settling of inclusions along an aluminum billet by applying deep etching on sample surfaces in different heights and subsequent counting of etch pits to determine the concentration of inclusions in different depths. ${ }^{[12]}$ There are few studies which investigated particle settling in-situ in metallic melts. Sztur et al. studied the particle settling in furnaces affected by the liquid aluminum motion experimentally and numerically. ${ }^{13]}$ Instone et al. developed a model to simulate the behavior of particles having different densities and sizes in the aluminum melting and holding furnaces and 
compared the results with experimental data. ${ }^{[14]}$ Martin et al. observed different trends during particle settling measured by LiMCA (Liquid Metal Cleanliness Analyzer) and concluded that different particle sizes and densities may be the reason for the different settling velocities observed during sedimentation. ${ }^{[1]}$ Badowski et al. investigated settling trends of oxide films, in 99.8 pct pure aluminum melt, using LiMCA technique. They reported that sedimentation in crucible furnaces is strongly influenced by thermal convection especially if the melt contains a large amount of films. ${ }^{[15]}$

The LiMCA measurement technique is based on the electric sensing zone principle and tracks the inclusions by measuring the change in electrical resistance between electrodes. This resistance change is caused by a particle passing through the orifice of a glass tube immersed in aluminum melt and obtained voltage peaks define the inclusion size and concentration. Inclusions between 20 and $300 \mu \mathrm{m}$ can be detected and the concentration is shown as kilo (particle) counts per $\mathrm{kg}$ of melt $(\mathrm{k} / \mathrm{kg}$ ) after each measurement cycle (60 to 90 seconds). ${ }^{[16,17]}$ LiMCA generates settling curves showing the concentration change over time and the monitored settling curves are usually defined by an exponential equation as follows:

$$
C=C_{0} \times e^{-k t},
$$

where $C$ is the inclusion concentration at time ' $t$ ', $C_{0}$ is the maximum inclusion concentration (start of settling), $k$ is the rate of settling, and $t$ is the settling time. The slope of the trendlines can be observed by the $k$ values which correspond to faster settling for higher $k$ values.

The current work presents a contribution to understanding the settling of non-metallic particles with different shapes in crucible furnaces with a special focus on the form effect on inclusion settling behavior. A LiMCA unit was used to track the particles in-situ during settling and PoDFA (Porous Disc Filtration Apparatus) to analyze the type of the particles. LiMCA results were evaluated by using exponential settling rates and an analytical model was developed to understand the LiMCA data and discuss parameters affecting particles while settling in different orientations.

\section{A. Governing Equations}

Under steady conditions, there are three main forces acting on a particle settling in a fluid, namely gravity " $F_{\mathrm{g}}$, " buoyancy " $F_{\mathrm{v}}$," and drag force " $F_{\mathrm{D}}$,"

The gravity and buoyancy forces acting on a particle are expressed as

$$
\begin{aligned}
& F_{g}=m_{p} \cdot g=\rho_{p} \cdot V_{p} \cdot g, \\
& F_{\mathrm{V}}=m_{\mathrm{f}} \cdot g=\rho_{\mathrm{f}} \cdot V_{\mathrm{p}} \cdot g,
\end{aligned}
$$

where $m_{\mathrm{p}}$ is the mass of the particle, $m_{\mathrm{f}}$ is the mass of the fluid displaced by the particle, $\rho_{\mathrm{p}}$ is the density of the particle, $\rho_{\mathrm{f}}$ is the density of the fluid, $g$ is the acceleration due to gravity, and $V_{\mathrm{p}}$ the particle volume.
The third force is the drag force, expressed as

$$
F_{\mathrm{D}}=\frac{1}{2} C_{\mathrm{D}} \rho_{\mathrm{f}} A_{\mathrm{p}} U_{\mathrm{p}}^{2},
$$

where $U_{\mathrm{p}}$ is the relative velocity between the melt and the particle, $A_{\mathrm{p}}$ is the particles area seen from the fluid, and $C_{\mathrm{D}}$ is the drag coefficient, dependent on the flow regime. For small particles, laminar flow conditions are typically assumed, with the classical Stokes drag law:

$$
C_{\mathrm{D}}=\frac{24}{\mathrm{Re}_{\mathrm{d}}},
$$

where $\mathrm{Re}_{\mathrm{d}}$ is the Reynolds number based on particle diameter expressed as

$$
\operatorname{Re}=\frac{\rho_{\mathrm{f}} U_{\mathrm{p}} d}{\mu}
$$

resulting in a drag (Stokes) on the form:

$$
F_{\mathrm{D}}=3 \pi \mu U_{\mathrm{p}} d,
$$

where $\mu$ is the viscosity of the melt.

Following Allen, ${ }^{[18]}$ particles are considered small if $\operatorname{Re} \leq 0.2$, corresponding to a critical particle size of

$$
D_{\mathrm{St}}^{3}=\frac{3.6 \mu^{2}}{\left(\rho_{\mathrm{p}}-\rho_{\mathrm{f}}\right) \rho_{\mathrm{f}} g} .
$$

The drag force, extended for non-spherical objects, is mainly used for the analytical settling calculations for different shapes. A correction factor that separates the drag force into two components, friction and form drag, is used to approximate the settling of non-spherical particles. The friction drag is calculated based on the diameter of a sphere having the same surface area as the settling non-spherical particle $\left(d_{\mathrm{s}}\right)$ and the form drag is calculated using the diameter of the sphere having the same projected area $\left(d_{\mathrm{n}}\right){ }^{[6]}$ The Stokes drag force under these circumstances as shown by Leith can be expressed as

$$
F_{\mathrm{D}}=3 \pi \mu U\left[(1 / 3) d_{\mathrm{n}}+(2 / 3) d_{\mathrm{s}}\right] .
$$

The shape-related part of the equation can be defined as shape factor " $K$ ":

$$
K=\left[(1 / 3) d_{\mathrm{n}}+(2 / 3) d_{\mathrm{s}}\right] .
$$

Defining the shape alone is not enough to predict the drag force or settling velocity because the same shape settling in different orientations will result in different settling velocities. The shape factor helps to approximate the terminal velocity of any shape moving with any orientation.

The shape of a particle is also explained by different approaches such as aspect ratio " $A_{\mathrm{R}}$." The aspect ratio of a particle is the ratio of its longest axis to its shortest axis which are expressed as follows ${ }^{[19]}$ :

$$
A_{\mathrm{R}}=\frac{d_{\max }}{d_{\min }} .
$$


Alternatively, to Stokes, the Schiller-Naumann ${ }^{[20]}$ drag coefficient is valid at moderate Re, extended by Tran-Cong et al. ${ }^{[10]}$ and expressed as

$$
\begin{aligned}
C_{\mathrm{D}}= & \frac{24}{\operatorname{Re}_{\mathrm{d}}} \frac{d_{\mathrm{A}}}{d_{\mathrm{n}}}\left[1+\frac{0.15}{\sqrt{c}}\left(\frac{d_{\mathrm{A}}}{d_{\mathrm{n}}} \operatorname{Re}\right)^{0.687}\right] \\
& +\frac{0.42\left(\frac{d_{\mathrm{A}}}{d_{\mathrm{n}}}\right)^{2}}{\sqrt{c}\left[1+4.25 \cdot 10^{4}\left(\frac{d_{\mathrm{A}}}{d_{\mathrm{n}}} \operatorname{Re}\right)^{-1.16}\right]},
\end{aligned}
$$

where $c$ is the particle circularity ${ }^{[10]}$ :

$$
c=\frac{\pi d_{\mathrm{A}}}{P_{\mathrm{p}}},
$$

where $P_{\mathrm{p}}$ is the perimeter of the particle projected in the settling direction, $d_{\mathrm{A}}$ is the surface equivalent sphere diameter, defined as

$$
d_{\mathrm{A}}=\sqrt{\frac{4 A_{\mathrm{p}}}{\pi}},
$$

$A_{\mathrm{p}}$ is the area of the particle projected in the settling direction. Finally, the volume equivalent sphere diameter is defined as

$$
d_{\mathrm{n}}=\left(\frac{6 V}{\pi}\right)^{1 / 3}
$$

where $V$ is the (actual) particle volume.

The Reynolds number in the above expression is based on $d_{\mathrm{n}}-$ i.e., ${ }^{[10]}$

$$
\operatorname{Re}_{\mathrm{d}}=\frac{\rho_{\mathrm{f}} U_{\mathrm{p}} d_{\mathrm{n}}}{\mu} .
$$

The steady force balance for a settling particle can be expressed as shown in Eq. [17], from which the terminal velocity $U_{\mathrm{p}}$ can be calculated either analytically for Stokes or numerically for Schiller and Naumann. ${ }^{[20]}$

$$
\frac{\pi}{6}\left(\rho_{\mathrm{p}}-\rho_{\mathrm{f}}\right) g d_{\mathrm{n}}^{3}-F_{\mathrm{D}}\left(U_{\mathrm{p}}\right)=0 .
$$

The effect of particle-particle interactions is finally estimated by using the Richardson-Zaki correlation [18, p. 274];

$$
U_{\mathrm{p}}^{\mathrm{h}}=U_{\mathrm{p}}\left(1-n_{\mathrm{tot}}\right)^{4.65},
$$

where $n_{\text {tot }}$ is the (total) volumetric particle concentration (dimensionless) and $U_{\mathrm{p}}^{\mathrm{h}}$ is the hindered settling velocity.

\section{B. Modeling of Particle Settling During LiMCA Measurements}

The settling velocities and LiMCA measurements are used to develop a simple model as follows:

The total number of particles of type $i, N_{i}$, present in a volume $\Delta V=A \Delta z$ is given as

$$
N_{i}=n_{i} \Delta V
$$

where $n_{i}$ is the (volumetric) number density of particles of the given type, i.e., size, aspect ratio, etc. The conservation of the $i$-th particle class is given by the continuity equation

$$
\frac{\partial n_{i}}{\partial t}+\nabla \cdot\left(\vec{U}_{i} n_{i}\right)=0
$$

where $\vec{U}_{i}$ is the settling velocity. Assuming unidirectional settling through a volume in which no particles enter through the top surface (e.g., the melt surface), the continuity equation can be written as

$$
\begin{aligned}
& \Delta V \frac{\mathrm{d} n_{i}}{\mathrm{~d} t}+A U_{z i} n_{i}=0 \\
& \rightarrow \frac{\mathrm{d} n}{\mathrm{~d} t}=-\frac{u_{z i}}{\Delta z} n_{i}
\end{aligned}
$$

with solution

$$
n_{i}(t)=n_{i 0} \exp \left(-\frac{u_{z i}}{\Delta z} t\right)=n_{i 0} \exp (-k t),
$$

where $n_{i 0}$ is the initial number density, $t$ is time, and $\Delta z$ is the vertical extent of the sampling volume, here assumed to be given by the immersion depth of the probe. The ratio $k=\frac{u_{z i} i}{\Delta z}$ is commonly denoted as the settling rate.

\section{Assessment of Flow Regimes for Typical Inclusions in Aluminum Melts}

Figure 1 presents the critical diameter of particles as a function of the density difference from 500 to $5000(\mathrm{~kg} /$ $\mathrm{m}^{3}$ ) with molten pure aluminum having the density of $2360 \mathrm{~kg} / \mathrm{m}^{3}$ and the dynamic viscosity of $0.00125 \mathrm{~kg} / \mathrm{m} \mathrm{s}$ at $720{ }^{\circ} \mathrm{C}$. The shown ranges include the most common inclusions present in aluminum melts, i.e., $\mathrm{Al}_{2} \mathrm{O}_{3}$, $\mathrm{MgO} \cdot \mathrm{Al}_{2} \mathrm{O}_{3}, \mathrm{MgO}, \mathrm{TiB}_{2}, \mathrm{TiC}$, and $\mathrm{SiC} . \mathrm{Al}_{4} \mathrm{C}_{3}$ is also commonly detected in aluminum melts but has almost the same density as the liquid aluminum, which results in a very high critical diameter (approximately $290 \mu \mathrm{m}$ ). This limit covers even the clusters since $\mathrm{Al}_{4} \mathrm{C}_{3}$ inclusions are typically found in diameter sizes of a few microns. ${ }^{[21]}$

Over the shown critical diameters, Stokes law will not be valid and can be misleading. Therefore, the modeling part of this study will focus on particles up to $50 \mu \mathrm{m}$. The reason for this limitation is the narrow Re range of Stokes flow regime. On the other hand, Schiller and Naumann ${ }^{[20]}$ approach is valid in the range $0.1<\operatorname{Re}<$ 800 and valid in the range $0.15<\operatorname{Re}<1500$ after the improvement by Tran-Cong. ${ }^{[10]}$ Due to the validity in moderate Re, the critical diameter for Schiller and Naumann ${ }^{[20]}$ drag will be higher than the critical diameter for Stokes.

Figure 2 shows settling velocities of discs settling in horizontal orientation with respect to the crucible bottom and spheres calculation by using Stokes and Schiller and Naumann ${ }^{[20]}$ drag. Both approaches show similar results for spheres and the difference increases with the increasing size. The deviation is 1 pct for particles $d=25 \mu \mathrm{m}, 4$ pct for particles $d=50 \mu \mathrm{m}$, and 16 pct for particles $d=100 \mu \mathrm{m}$. On the other hand, 


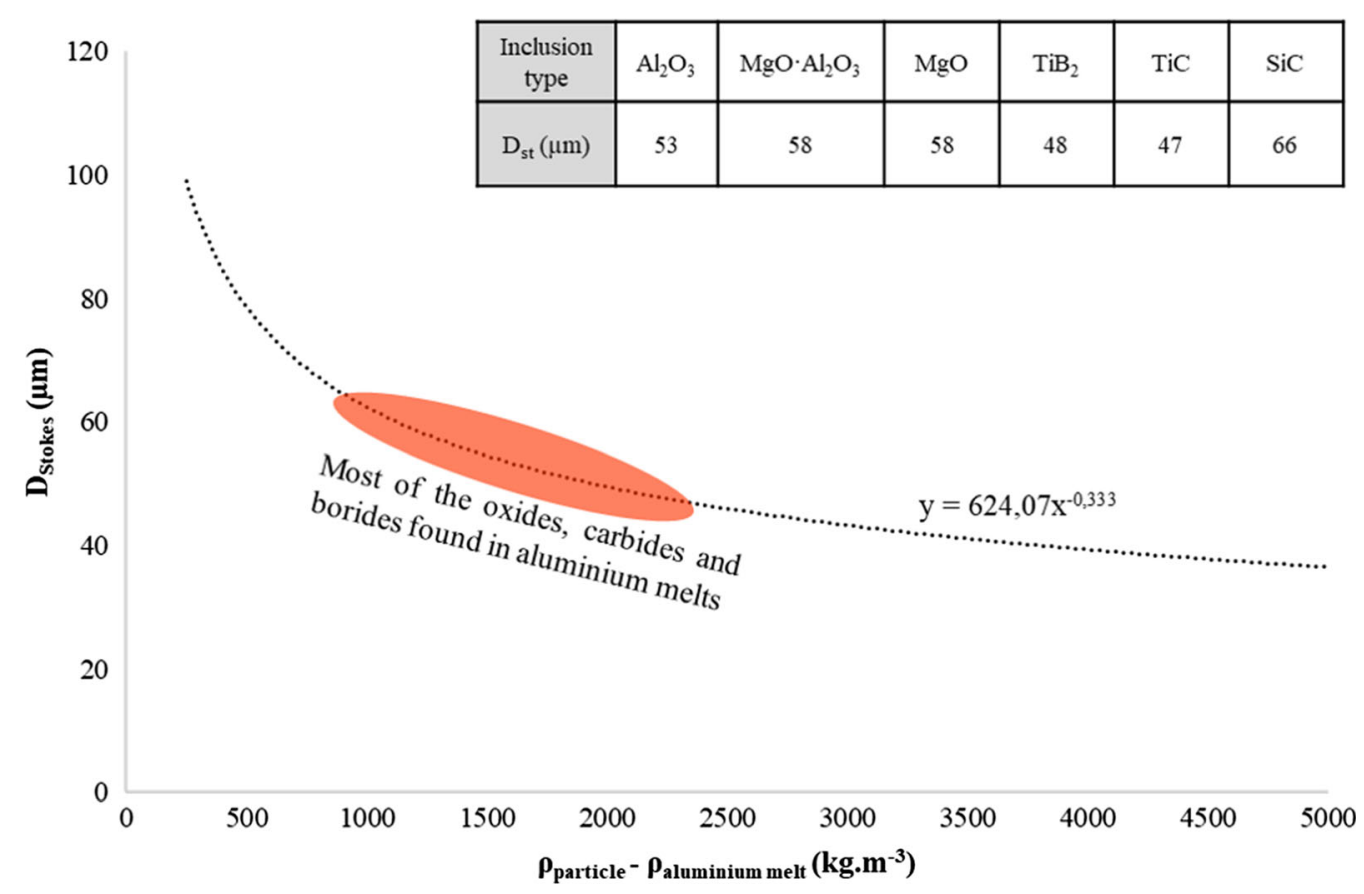

Fig. 1 - Critical diameter of particles in pure aluminum melts with different density gradients.

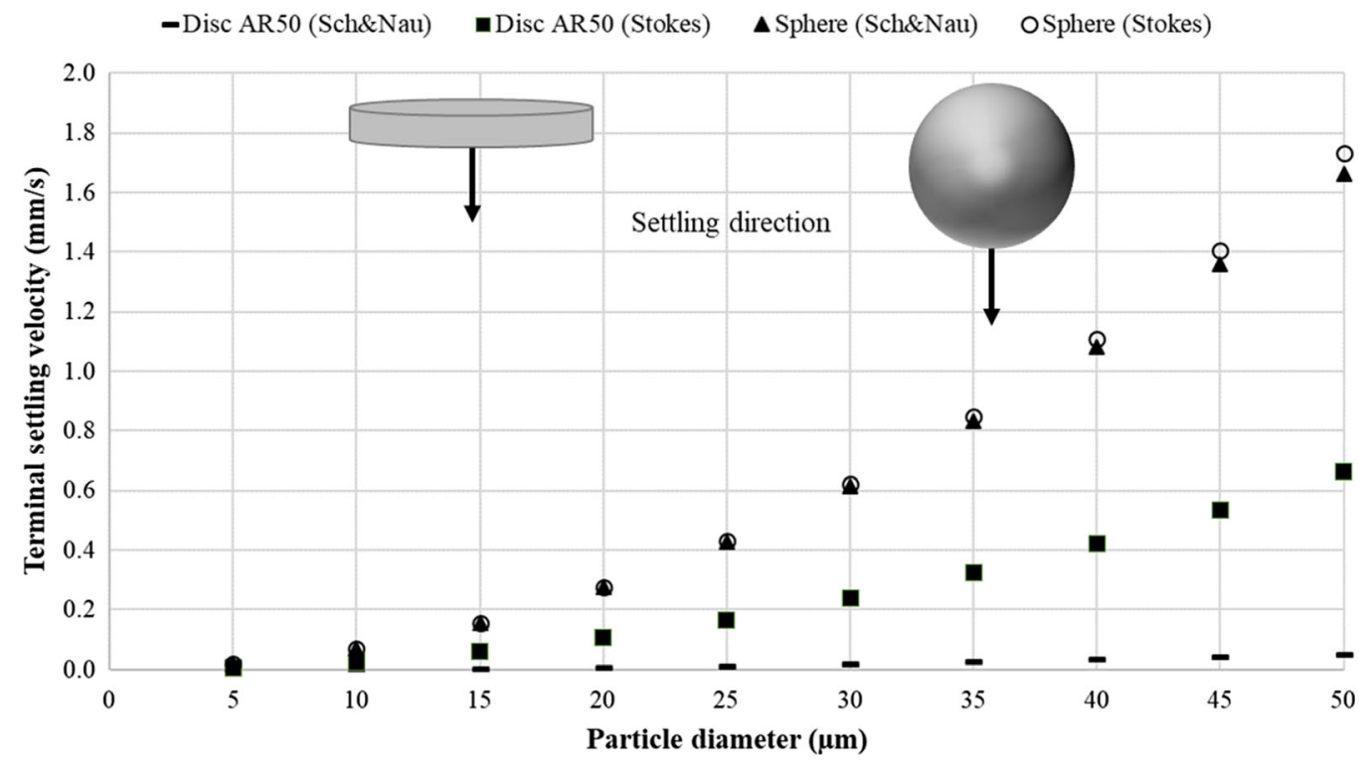

Fig. 2 - Calculated velocities of settling discs with $A_{\mathrm{R}}=50$ and spheres by using Stokes and Schiller and Naumann ${ }^{[20]}$ drag.

velocity results for discs, calculated using Stokes drag, show approximately 13 times larger values than the Schiller and Naumann ${ }^{[20]}$ drag. The reason for this difference is that most of the inclusions in liquid aluminum after filtration are below $50 \mu \mathrm{m}$ (in average $29 \mu \mathrm{m}$ in this study) which typically corresponds to $\mathrm{Re}_{\mathrm{p}}$ $<0.15$ for spheres and even lower for discs with $\mathrm{Ar}=$ 50 (representing films). Hence, Stokes approach for spheres and irregular shapes by using $d_{\mathrm{A}}$ and $d_{\mathrm{n}}$ will be used in the current study.

\section{Experimental Methodology and Materials}

An aluminum alloy with 99.8 pet purity was molten in a resistance heated crucible furnace with the capacity of $120 \mathrm{~kg}$ melt shown in Figure 3. Samples were taken from the surface for the PoDFA characterization in stirred and settled conditions to have better information about the inclusion chemistries. The PoDFA method is a qualitative and quantitative method for evaluation of inclusion concentration and type. Approximately $1 \mathrm{~kg}$ of 

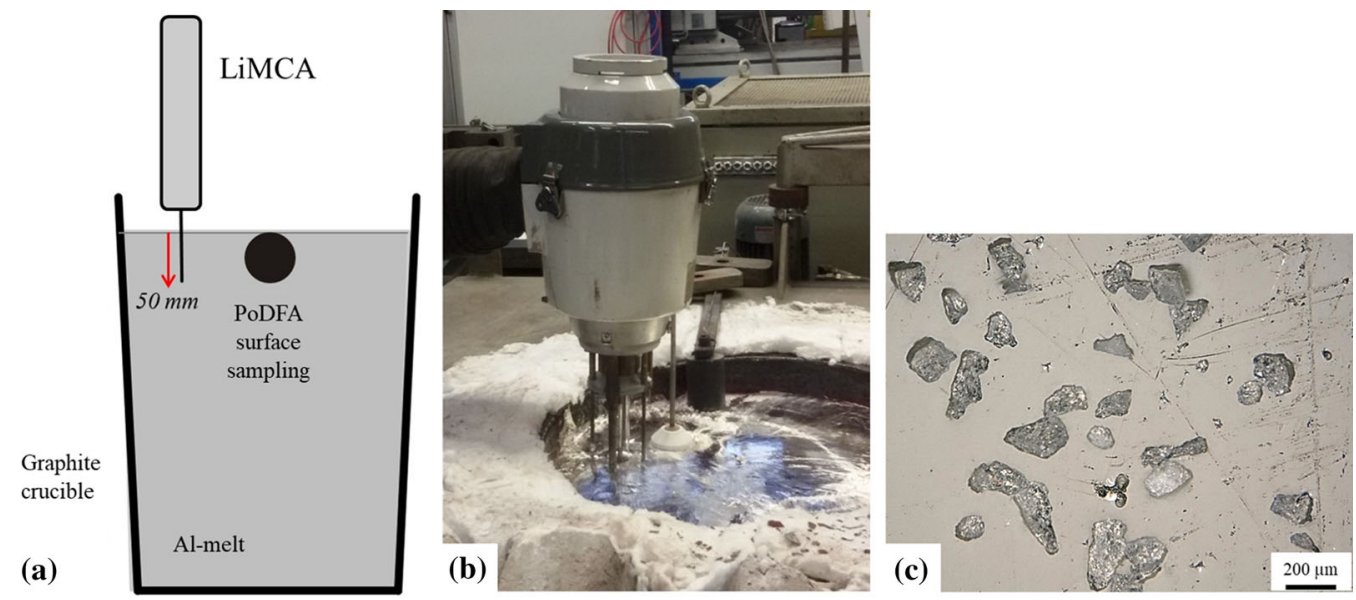

Fig. 3 - (a) Schematic view of the experimental setup, (b) the LiMCA unit immersed in the melt, (c) deliberately added spinel oxide particles.
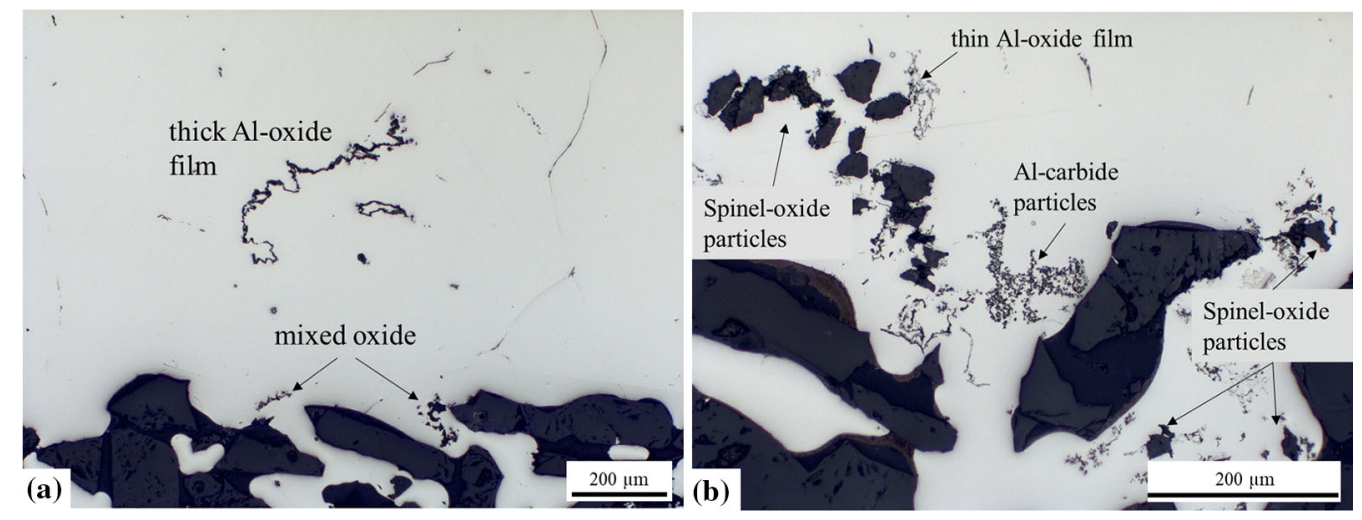

Fig. 4 - (a) Oxide films and mixed oxide particles (before particle addition), (b) spinel oxide, aluminum carbide particles and films (after particle addition) found in the PoDFA samples.

melt is filtered and the inclusions are concentrated above a filter which is metallographically examined after some preparation steps. ${ }^{[22]}$

The melt was stirred to homogenize the inclusion concentration through the melt volume and the LiMCA unit tracked the concentration change of particles as a function of time. Four tests were carried out without addition of different particles and one test was done after addition of spinel oxide particles in the size range of 20 to $40 \mu \mathrm{m}$ (as prefabricated metal matrix composites) with an aspect ratio up to 5. The settling behavior of particles was monitored during each test and the concentration change data were post-processed to interpret the settling rate of the particles.

\section{RESULTS AND DISCUSSION}

\section{A. Characterization of the Inclusions Present in a 99.8} Pct Pure Aluminum Melt

PoDFA results showed that the starting inclusion families of the melt mainly consist of $\mathrm{Al}_{2} \mathrm{O}_{3}$ films, mixed oxides, and $\mathrm{Al}_{4} \mathrm{C}_{3}$ particles (Figure 4). $\mathrm{Al}_{2} \mathrm{O}_{3}$ films corresponds to approximately 50 pct of the inclusions in similar melts with $>99.7$ pct purity as reported in the previous work. ${ }^{[15]}$ The thickness of $\mathrm{Al}_{2} \mathrm{O}_{3}$ thin films is usually under $1 \mu \mathrm{m}$ and the cross-section can vary between 10 and $500 \mu \mathrm{m} \cdot{ }^{[23]} \mathrm{Al}_{4} \mathrm{C}_{3}$ particles are usually very fine and cannot be detected by LiMCA since it is not capable of measuring the particles below 17 microns with standard 


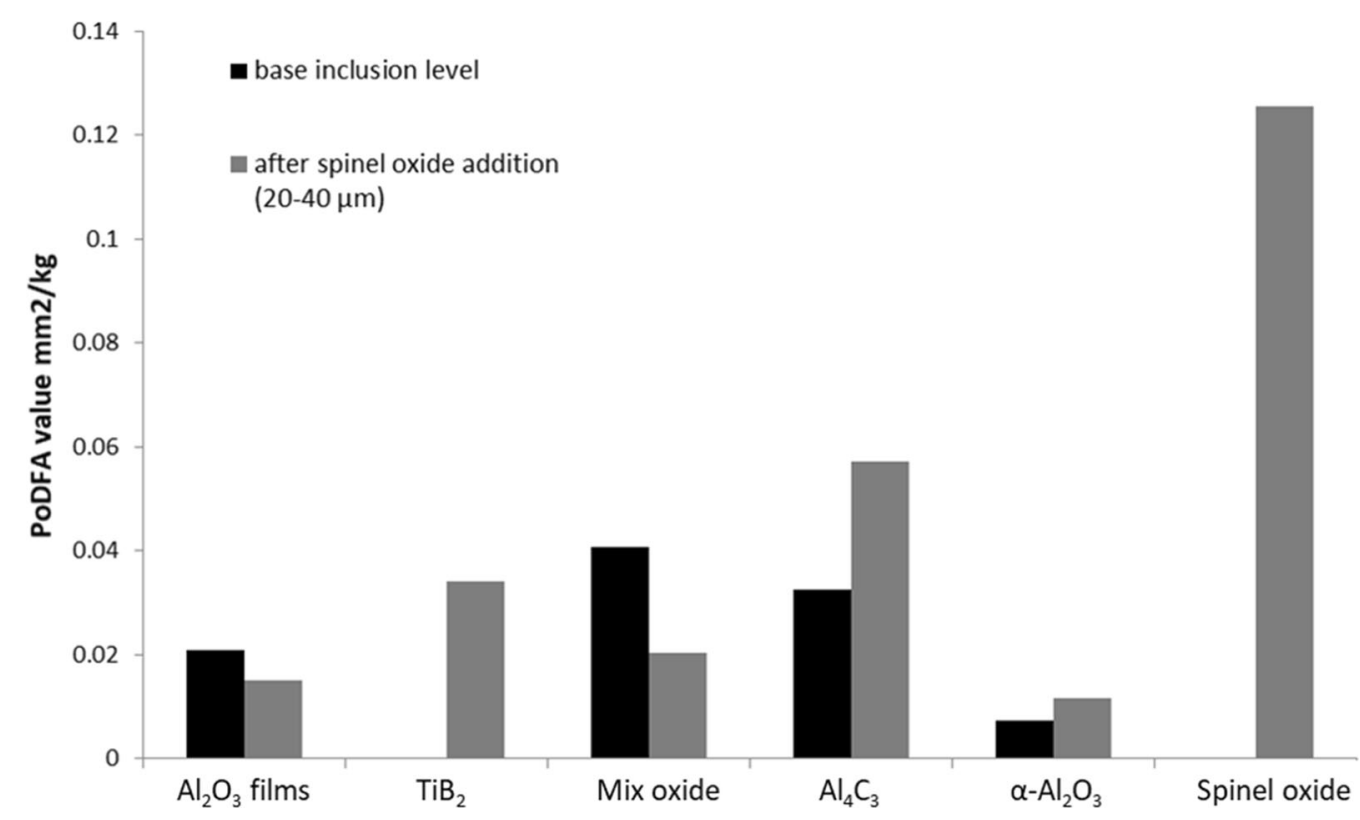

Fig. 5-PoDFA results of 99.8 pct pure aluminum melt before and after spinel oxide addition expressed in $\mathrm{mm}^{2} / \mathrm{kg}$.

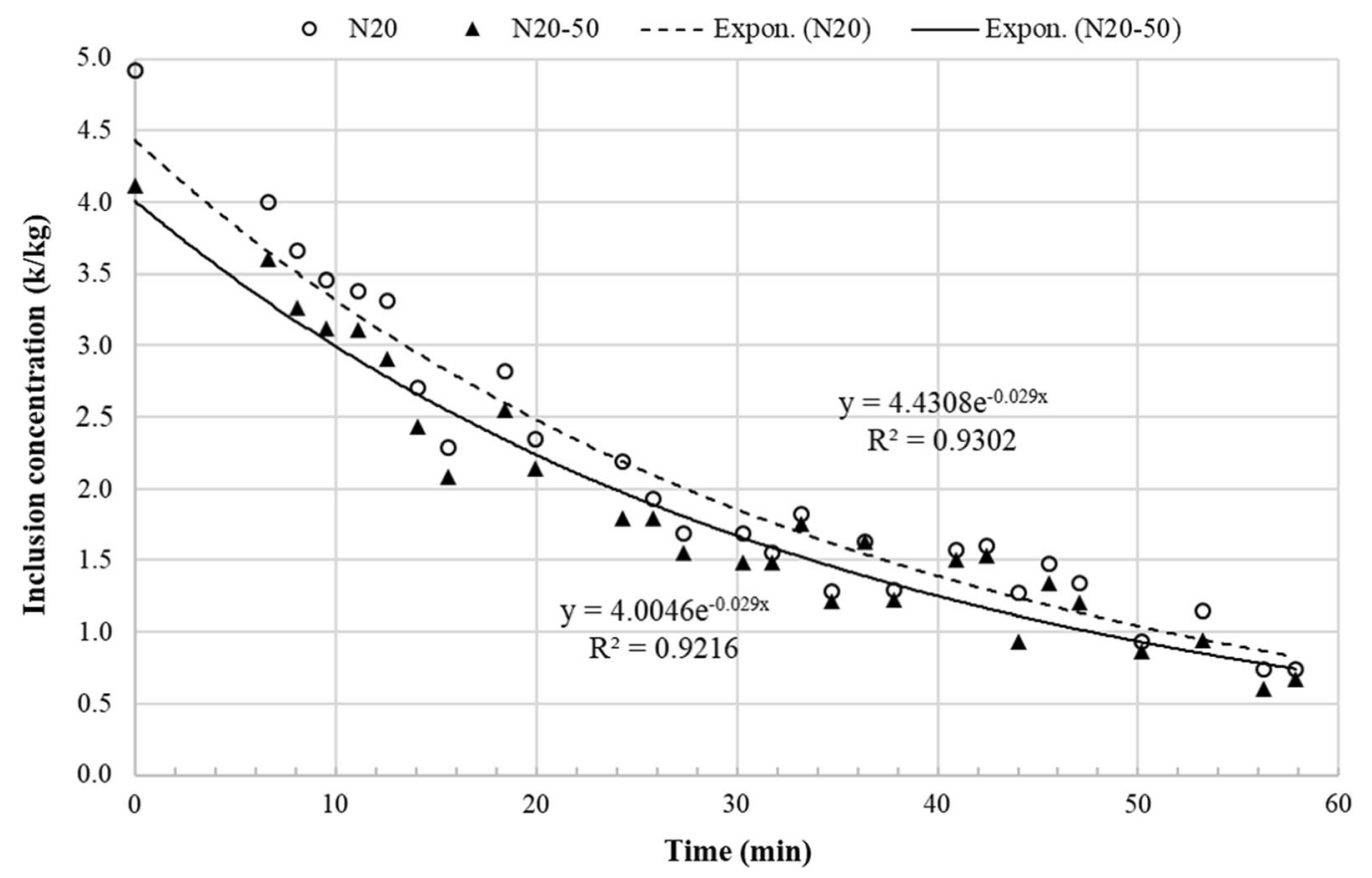

Fig. 6- Settling trend of the inclusions monitored by LiMCA after stirring.

setups. ${ }^{[2]}$ Therefore, the LiMCA curve presents predominantly the films in pure melts. The added spinel oxide particles were clearly detected by PoDFA. The concentration and microscopic pictures are shown in Figures 4 and 5. Thus, both spinel oxide particles and alumina films were measured in test 5 during sedimentation.

\section{B. LiMCA Settling Results}

Four LiMCA trials were performed without particle addition and one example settling curve is shown in Figure 6. It shows the concentration change for inclusions over $20 \mu \mathrm{m}$ (N20) and 20 to $50 \mu \mathrm{m}$ (N20-50). The data for particles 20 to $50 \mu \mathrm{m}$ are used to compare with the analytical model which is valid in Stokes regime. Both curves show the same settling rate " $k=0.029$ " indicating that the settling is dominated by the size range 20 to 50 due to lower concentration of inclusions larger than $50 \mu \mathrm{m}$.

The similar settling rates and the behavior were observed in other experiments with using the same alloy and the results are shown in Table I. The exponential coefficients show the $k$ value of 0.033 in average. 
Figure 7 shows the settling measurements after particle addition (Test 5) and the characteristic of the settling is clearly different from the base-level inclusions. The settling trend after particle addition cannot be described by only one settling curve anymore. Two different trends are observed due to inclusions having different shapes therefore, the new behavior can be studied in two parts with different settling rates as already mentioned in the previous study. ${ }^{[25]}$ The faster settling is mainly influenced by the added particles and the slower behavior is close to the base inclusion settling trends.

\section{Modeling Results Based on LiMCA Data}

The starting inclusion concentration of particles in the size range of 20 to $50 \mu \mathrm{m}$ was taken as $n_{i 0}$ in Eq. [22] for the modeling calculations. To simplify the model, the weighted average diameter was calculated as diameter according to the LiMCA data in Table II. The starting inclusion concentration of the melt was $4.11 \mathrm{k} / \mathrm{kg}$ with an average equivalent diameter of $29 \mu \mathrm{m}$. The values increased to $15.61 \mathrm{k} / \mathrm{kg}$ and $32 \mu \mathrm{m}$ after the addition of spinel oxide particles.

The analytical model has been designed to approximate the settling behavior for spherical, cylindrical, and disc-shaped $\mathrm{Al}_{2} \mathrm{O}_{3}$ particles $\left(3950 \quad \mathrm{~kg} / \mathrm{m}^{3}\right)$ and $\mathrm{Al}_{2} \mathrm{O}_{3} \cdot \mathrm{MgO}$ particles $\left(3600 \mathrm{~kg} / \mathrm{m}^{3}\right)$ in an aluminum melt

Table I. Overview of Inclusion Settling Rates in 99.8 Pct Aluminum Alloys

\begin{tabular}{lllll}
\hline Tests & 1 & 2 & 3 & 4 \\
$-k(\mathrm{~N} 20)$ & 0.029 & 0.031 & 0.035 & 0.036 \\
\hline
\end{tabular}

N20-50. with the density of $2360 \mathrm{~kg} / \mathrm{m}^{3}$ and the viscosity of $1.25 \cdot 10^{3} \mathrm{~kg} / \mathrm{m} / \mathrm{s}$ at $720{ }^{\circ} \mathrm{C}$. The settling velocities of particles were studied in different aspect ratios and settling orientations (Table III) in the model to investigate the shape and settling orientation effects on sedimentation.

The shape factor " $K$ " (Eq. [10]) was calculated for each variable parameter mentioned in Table III. The $K$ values of each particle are divided by the $K$ value of the sphere to normalize the data. The ratios " $K_{\text {particle }}$ $K_{\text {sphere }}$ "are shown in Figure 8 as a function of settling velocity. The effect of the shape factor of particles with the same volume and density (same $F_{\mathrm{G}}$ and $F_{\mathrm{V}}$ in the fluid), is clearly seen in the diagram and the settling velocity decreases with increasing " $K$." The relation seems to be exponential with an acceptable fit $\left(R^{2}=\right.$ 0.9777). Clustering of particles will also affect the settling due to increasing mass and decreasing drag (minimization of the surface energy) but this effect is neglected in this study.

Furthermore, the sphere was chosen as reference shape and discs with $A_{\mathrm{R}}=50$ as an approximation to films in the melt. The calculated settling data is shown in Figure 9 together with data measured with LiMCA. The settling velocity of discs both in horizontal and vertical orientations $(\mathrm{H}, \mathrm{V})$ with respect to the crucible bottom presents a faster settling than the measured data. The model represents free settling without any melt flow influence on particles. However, in practice, it is known that a considerable melt flow will be generated due to thermal convection. The difference between the model and the measured data is mainly due to the melt flow effect. The melt flow in the crucible was numerically modeled and reported that melt flow can reach up to $0.009 \mathrm{~m} / \mathrm{s}$ in different regions around the sampling position. This flow will affect the movement of some particles especially the films. Since the flow is

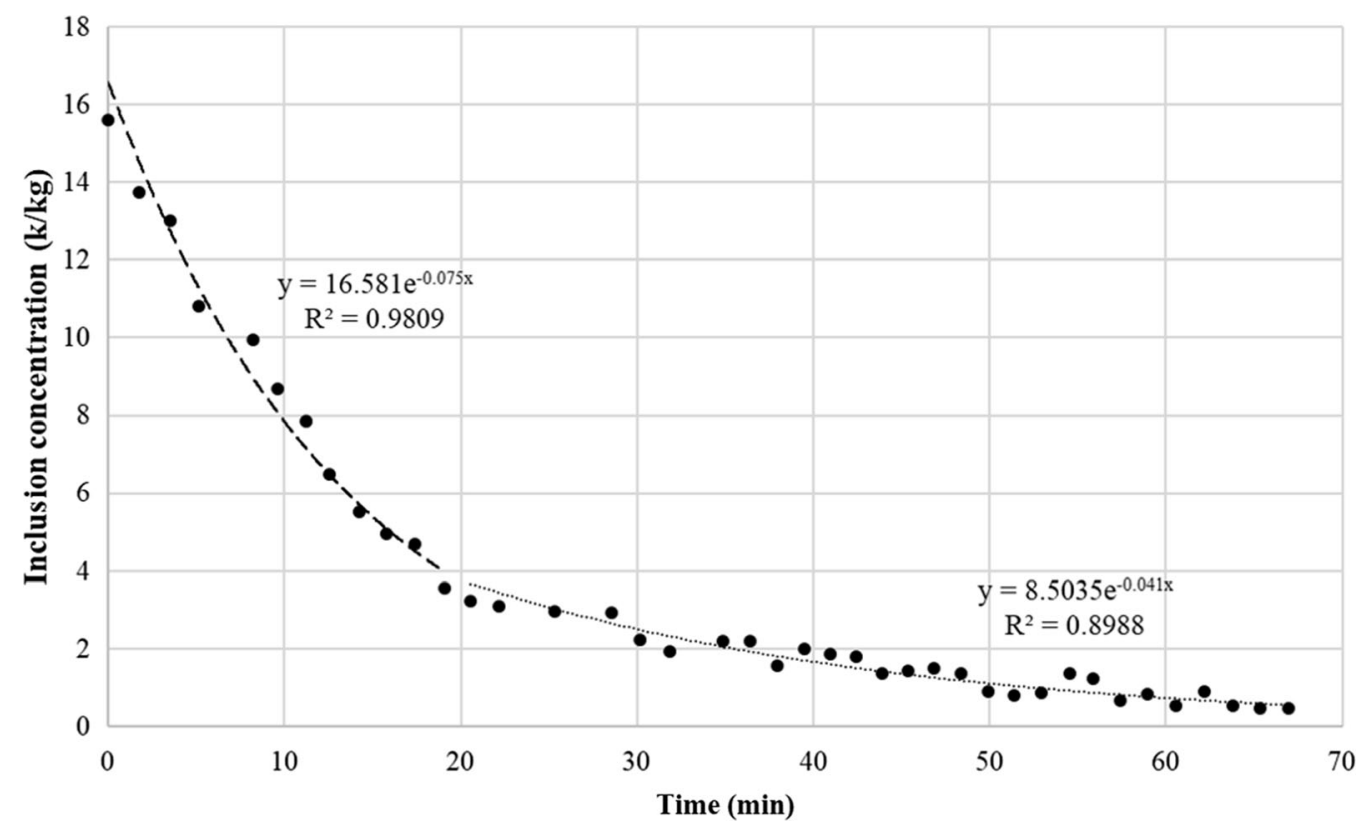

Fig. 7-Different settling trends monitored by LiMCA after addition of $\mathrm{Al}_{2} \mathrm{O}_{3} \cdot \mathrm{MgO}$ particles (Test 5). 
Table II. Inclusion Concentration Measured After Stirring the Melt

\begin{tabular}{llllllll}
\hline Base Inclusion Level & size range $(\mu \mathrm{m})$ & 20 to 25 & 25 to 30 & 30 to 35 & 35 to 40 & 40 to 45 & 45 to 50 \\
& concentration $(\mathrm{k} / \mathrm{kg})$ & 1.75 & 0.88 & 0.61 & 0.47 & 0.20 \\
After Particle Addition & size range $(\mu \mathrm{m})$ & 20 to 25 & 25 to 30 & 30 to 35 & 35 to 40 & 40 to 45 & 45 to 50 \\
& concentration $(\mathrm{k} / \mathrm{kg})$ & 5.04 & 2.69 & 2.69 & 2.07 & 1.24 \\
\hline
\end{tabular}

Table III. Variable Parameters in the Model

\begin{tabular}{lcc}
\hline Particle Geometry & Aspect Ratio $\left(A_{\mathrm{R}}\right)$ & Approximation To \\
\hline Sphere & 1 & reference \\
Disc & 5 & shape of added particles \\
Disc & 50 & shape of thin films \\
\hline
\end{tabular}

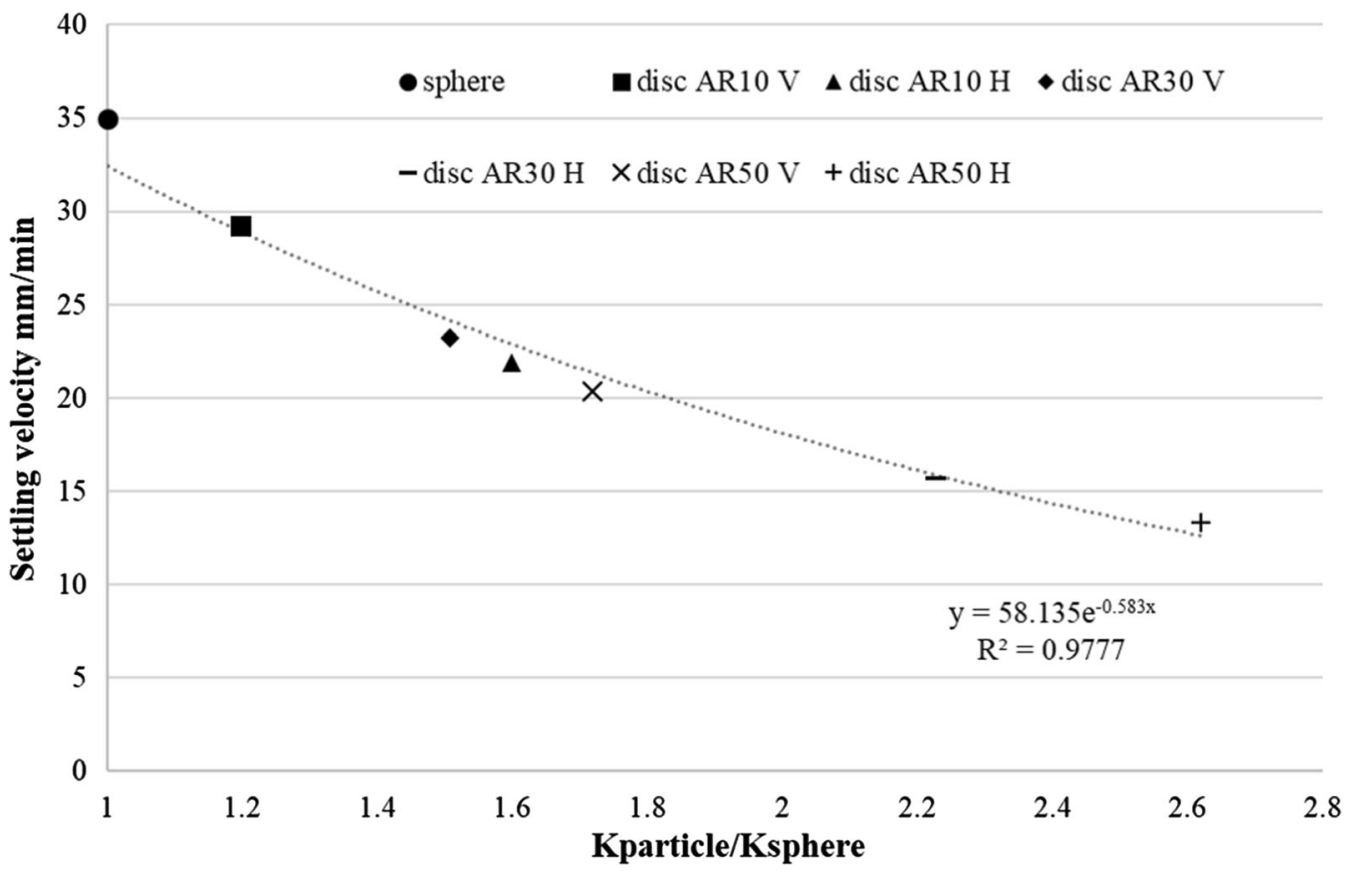

Fig. 8- Shape factor effect on settling velocity of a sphere and discs with different aspect ratios.

non-uniform, (flow in upwards direction close to the walls and in downwards direction at the center) it can promote or hinder the settling in different pathways. ${ }^{[15]}$

The settling velocity can be also affected by interactions between particles. This interaction increases the drag during settling and causes a disagreement between theoretical and experimental data. The correction of this error is shown in Eq. [18]. Richardson and Zaki ${ }^{[26]}$ reported that concentrations $<0.2$ give an error close to zero. In the current study, the highest particles measured particle concentration was approximately $20 \mathrm{k}$ particles per $\mathrm{kg}$ of aluminum melt which corresponds to $1 \mathrm{ppm}$ of inclusions. Therefore, the deviation between the theoretical the hindered velocity was neglected.
$0.2 \mathrm{~mm} / \mathrm{s}$ melt flow was added opposite to the settling direction and the new settling trends were obtained. The new trends with the presence of the melt flow are shown in Figure 10. The effect of the melt flow is clearly seen and even a moderate melt velocity of $0.02 \mathrm{~mm} / \mathrm{s}$ has a considerable effect on a particle with a high surface area.

The settling velocities were recalculated with \pm 10 pct of the measured melt velocity shown in Figure 11 to observe the extent of the melt flow effect. Particles with the highest surface area limit the sedimentation efficiency in the refining step. Because such particles have quite low settling velocities they are easily dragged, and the importance of the melt flow increases. 


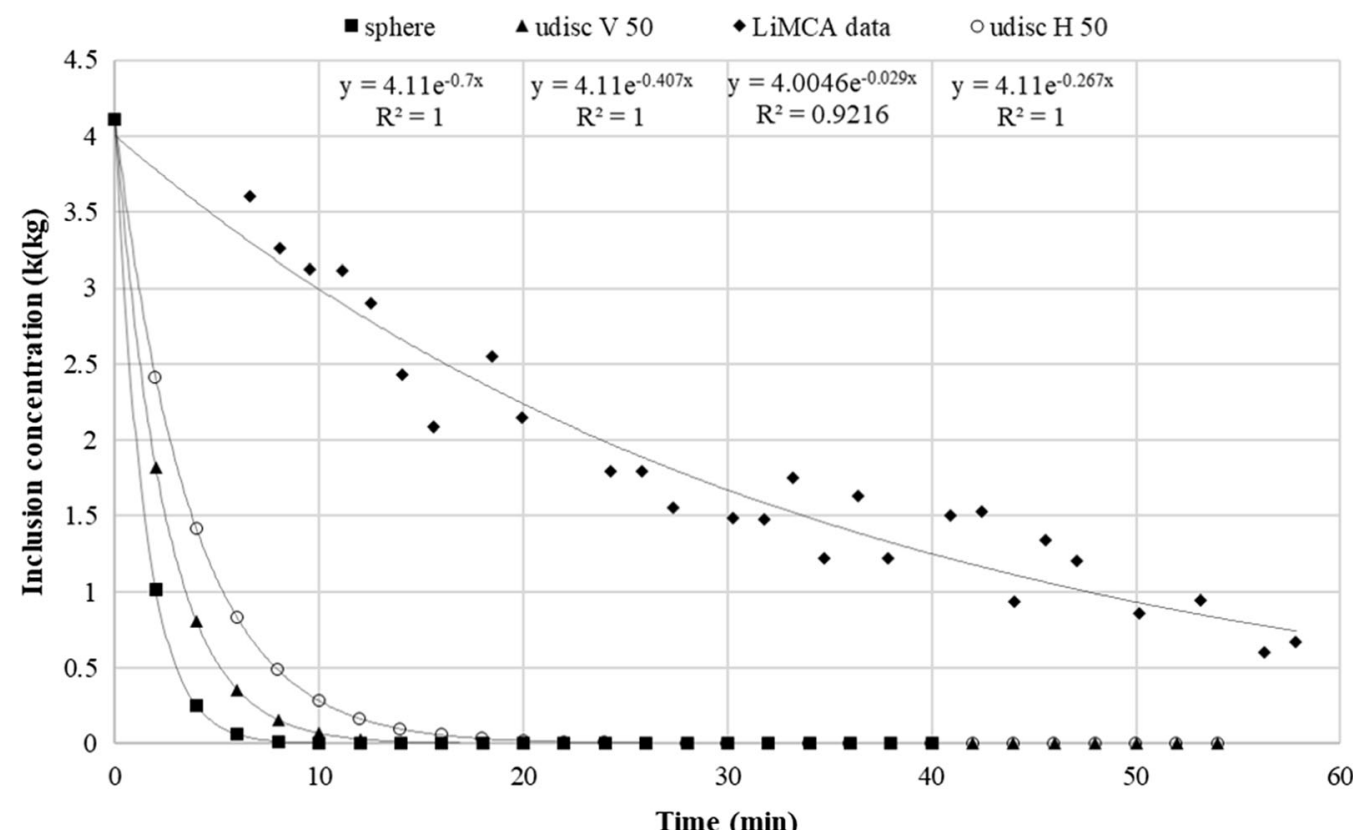

Fig. 9-Free settling behavior of discs and spheres in comparison with the LiMCA data.

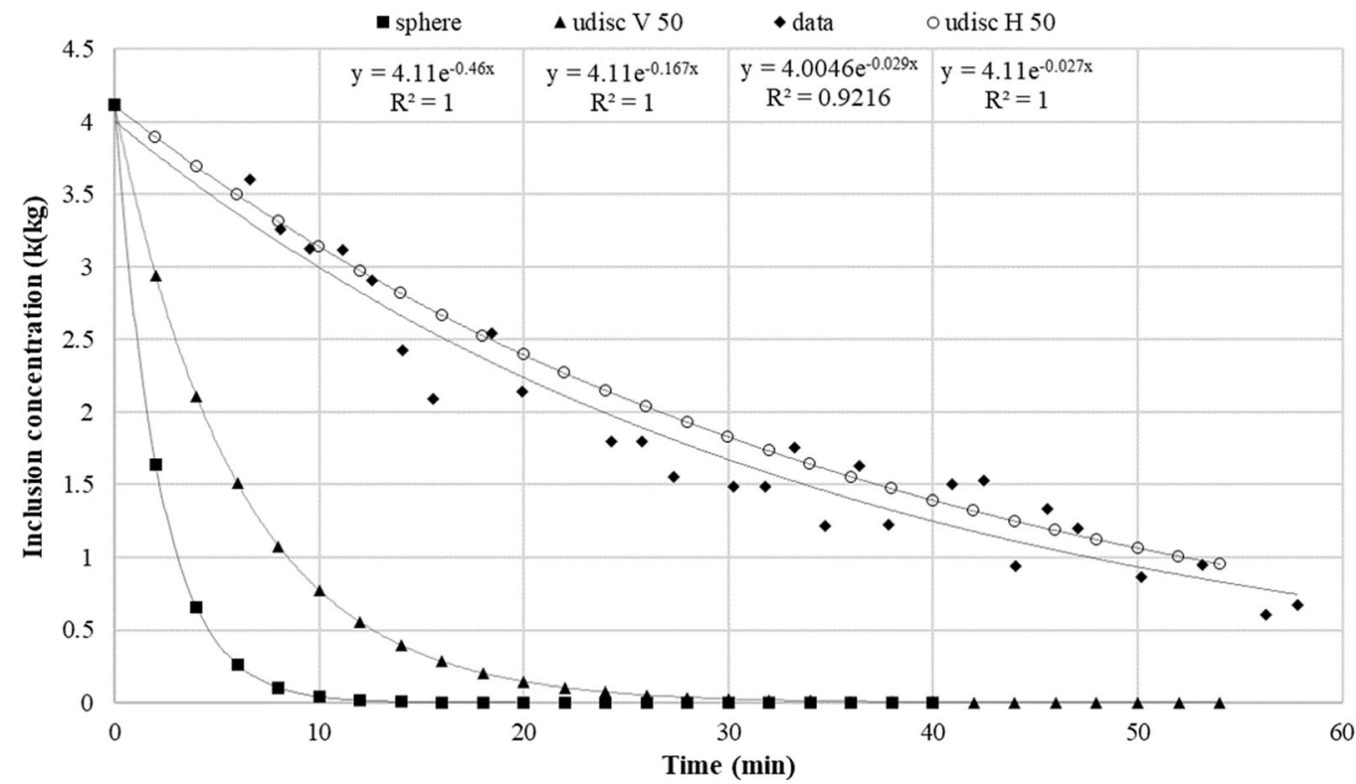

Fig. 10 - Settling behavior of discs and spheres under the effect of melt flow $(0.2 \mathrm{~mm} / \mathrm{s})$ in comparison with the LiMCA data.

The model was also used to study the changed settling characteristic after particle addition. The concentration before particle addition (4.11 kcounts $/ \mathrm{kg}$ ) was assumed as concentration of the alumina films (disc with AR:50 in horizontal orientation) and the rest of the concentration $(=15.61$ to $4.11 \mathrm{kcounts} / \mathrm{kg})$ was assumed to be added particles. The settling velocity of non-spherical particles (assumed as discs with $A_{\mathrm{R}}=5$ ) was compared with the spherical particles with the same volume. The ratio " $U_{\text {disc }} / U_{\text {sphere" }}$ is shown in Figure 12 and the settling velocity of a disc with an aspect ratio of 5 corresponds to an approximately 20 pct of a sphere.
Therefore, the settling velocity was set to $20 \mathrm{pct}$ slower than a spherical spinel oxide particle, as an approximation and settling after particle addition was modeled (Figure 13) accordingly. The settling rates measured by LiMCA are slower than the model prediction, similar to previous results.

The analytical model has shown similar results with the LiMCA data for both conditions (before and after addition of particles). The effect of the particle shape on settling velocity can be obviously seen both in measured and calculated results. Since LiMCA does not provide the shape of tracked inclusions, a detailed 


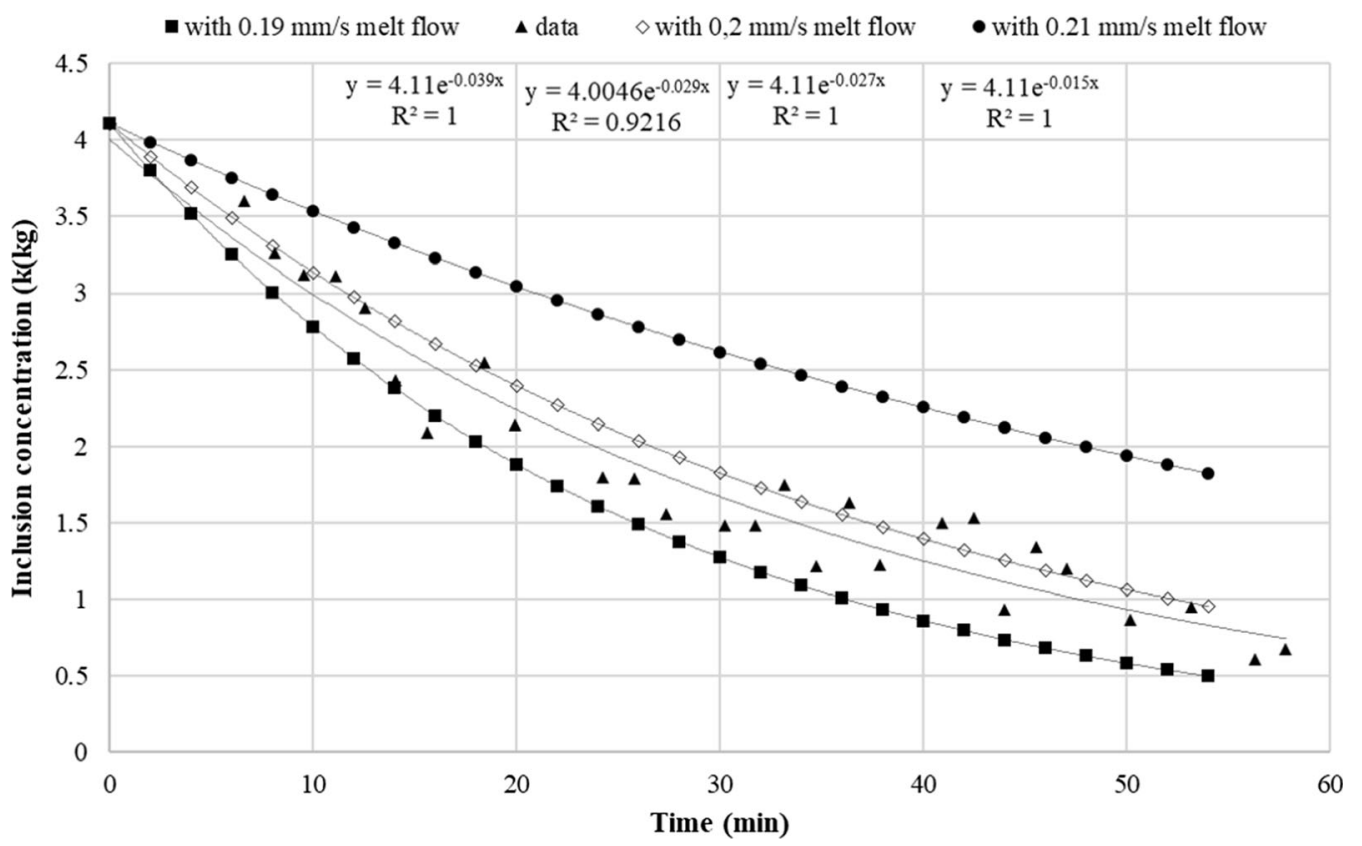

Fig. $11-$ Settling behavior of $\operatorname{discs}\left(A_{\mathrm{R}}=50\right)$ in horizontal orientation under different melt flow velocities in comparison with the LiMCA data.

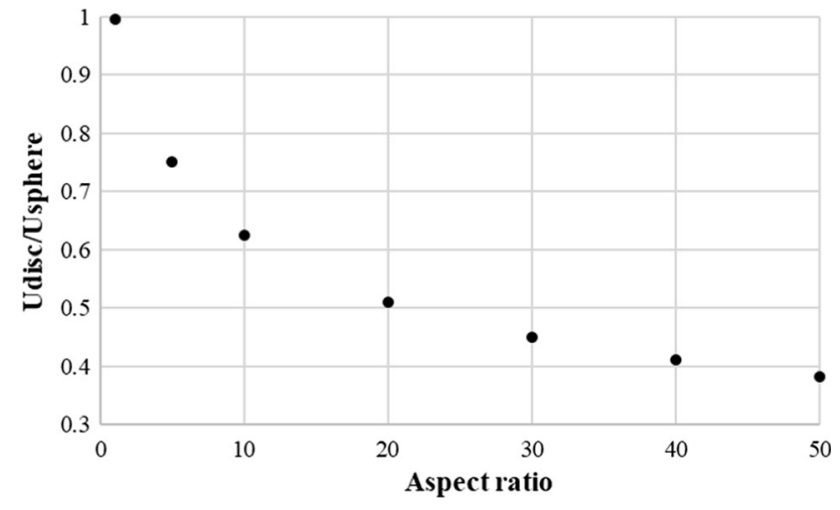

Fig. 12 - Settling velocity of cylinders with different aspect ratios in comparison with a sphere with the same volume.

characterization is always necessary for a precise modeling. In addition, the effect of orientation of particles during settling is clearly an important parameter as reported in calculated results but, it is impossible to track this parameter by the LiMCA method.

\section{CONCLUSIONS}

The settling of particles and films was studied in a demo-scale crucible furnace by LiMCA measurements. LiMCA data were used as comparison for a simple analytical particle settling model. The results can be summed up as follows:

- Most of the inclusions in aluminum melts have $\operatorname{Re}>$ 0.15 due to their small size and the Stokes drag force can be used to model the settling of inclusions under these conditions
- Critical diameters for settling of most common inclusions in aluminum melts were found in the range of 48 to $66 \mu \mathrm{m}$. Stokes law can give misleading results for particle sizes over these critical diameters.

- The effect of particle orientation and shape on particle settling velocity has been clearly observed in the model. This fact rises the importance of settling characteristic of a particle assumed for the modeling the non-spherical particles in melts.

- Melt velocity has a large effect on sedimentation, especially for particles having a large surface or small diameters. This points out the importance of temperature control and design of holding furnaces in order to reduce the melt flow due to the thermal convection during particle settling.

\section{ACKNOWLEDGMENTS}

Open Access funding provided by NTNU Norwegian University of Science and Technology (incl St. Olavs Hospital - Trondheim University Hospital). The research leading to these results has been carried out within the framework of the AMAP (Advanced Metals and Processes) research cluster at RWTH Aachen University, Germany. The assistance of Susanna Giulia Barberi, carrying out the experiments, is gratefully acknowledged.

\section{OPEN ACCESS}

This article is licensed under a Creative Commons Attribution 4.0 International License, which permits use, sharing, adaptation, distribution and reproduction 


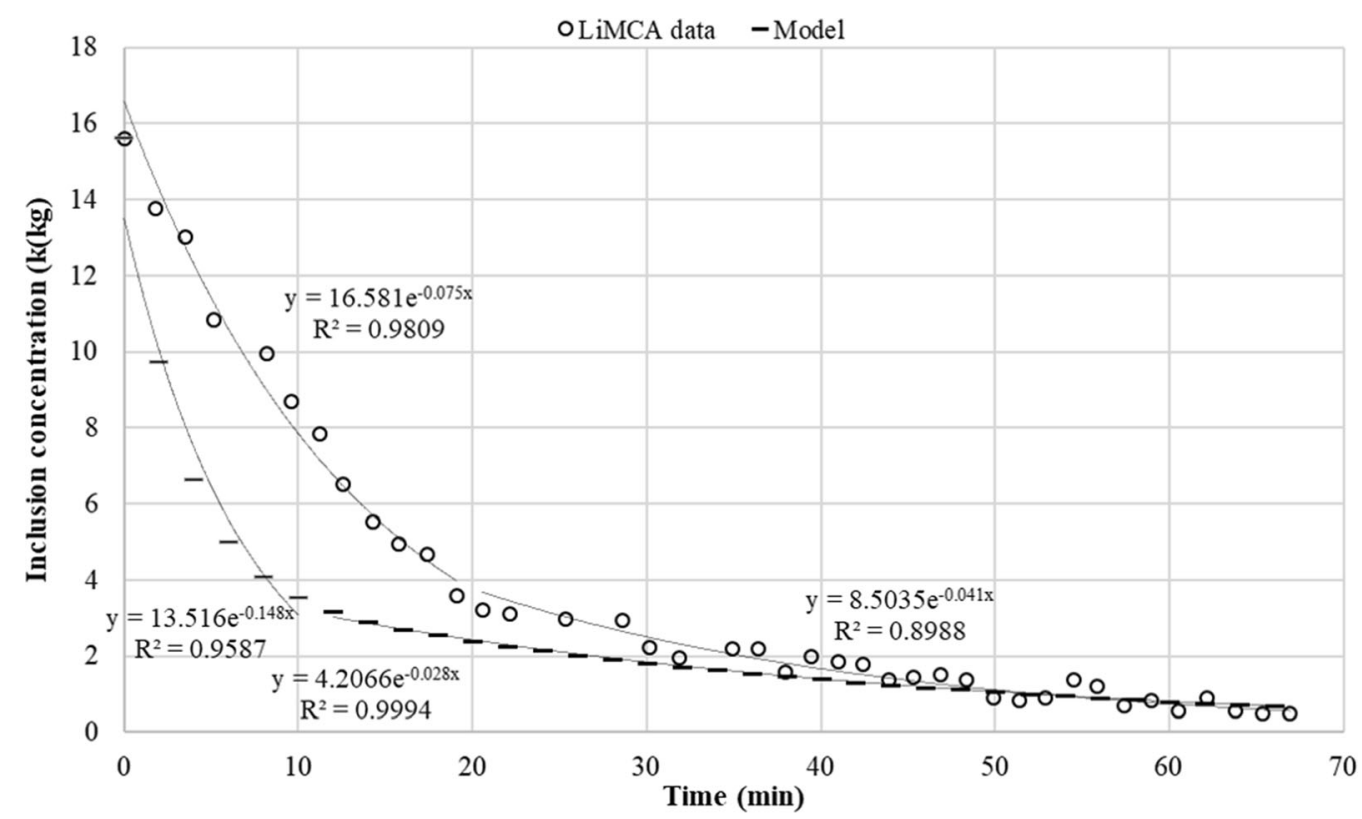

Fig. 13 - Settling trend of the inclusions monitored by LiMCA after addition of $\mathrm{Al}_{2} \mathrm{O}_{3} \cdot \mathrm{MgO}$ particles.

in any medium or format, as long as you give appropriate credit to the original author(s) and the source, provide a link to the Creative Commons licence, and indicate if changes were made. The images or other third party material in this article are included in the article's Creative Commons licence, unless indicated otherwise in a credit line to the material. If material is not included in the article's Creative Commons licence and your intended use is not permitted by statutory regulation or exceeds the permitted use, you will need to obtain permission directly from the copyright holder. To view a copy of this licence, visit http://creativec ommons.org/licenses/by/4.0/.

\section{REFERENCES}

1. J.P. Martin, G. Dube, D. Frayce, and R. Guthrie: TMS Light Metals, TMS-AIME, Phoenix, 1988, pp. 445-55.

2. B. Friedrich, C. Kräutlein, K. Krone, Continuous Casting: Proceedings of the International Conference on Continuous Casting of Non-Ferrous Metals, 2006, pp. 1-22.

3. M. Rosso and I. Peter: Mater. Manuf. Eng., 2012, vol. 52, pp. 59 66.

4. F. Frisvold, T.A. Engh, S.T. Johansen, T. Pedersen, and F. Frisvold: TMS Light Metals, TMS, Warrendale, 1992, pp. 1125-31.

5. G. Stokes: Mathematical and Physical Papers, Cambridge University Press, Cambridge, 1880, p. 1.

6. D. Leith: Aerosol Sci. Technol., 1987, vol. 6, pp. 153-61.

7. W.E. Dietrich: Water Resour. Res., 1982, vol. 18, pp. 1615-26.

8. M. Hartman, O. Trnka, and K. Svoboda: Ind. Eng. Chem. Res., 1994, vol. 33, pp. 1979-83.

9. K.G. Tsakalakis and G.A. Stamboltzis: Miner. Eng., 2001, vol. 14 , pp. $349-57$.
10. S. Tran-Cong, M. Gay, and E.E. Michaelides: Powder Technol., 2004, vol. 139, pp. 21-32.

11. C.J. Simensen: Metall. Trans. B, 1981, vol. 12, pp. 733-43.

12. G. Razaz and T. Carlberg: TMS Light Metals, Wiley, Hoboken, 2013, pp. 987-91.

13. C. Sztur, F. Balestreri, J. Meyer, and B. Hannart: TMS Light Metals, TMS, Warrendale, 1990, pp. 107-14.

14. S. Instone, A. Buchholz, and G.U. Gruen: TMS Light Metals, TMS, Warrendale, 2008, pp. 811-16.

15. M. Badowski, M. Gökelma, J. Morscheiser, T. Dang, P. Le Brun, and S. Tewes: TMS Light Metals, Mertol Gökelma, Nashville, 2015, pp. 965-72.

16. M. Li and R.I.L. Guthrie: ISIJ Int., 2001, vol. 41, pp. 101-10.

17. Automatic LiMCA II Automation and Maintenance Guide, REV.2.2; ABB Bomem Inc., 2003.

18. T. Allen, Particle size measurement, 5th ed., Chapman \& Hall, London, 1996-1997.

19. H. Wadell: J. Geol., 1935, vol. 43, pp. 250-80.

20. L. Schiller and A. Naumann: Ver. Deutch Ing., 1933, vol. 77, pp. $318-20$.

21. J. Courtenay and W. Schneider: Filtration of Aluminium Melts, Pyrotek Engineering and VAW Aluminium AG R\&D, Bonn, 2000.

22. D. Doutre, B. Gariépy, J.P. Martin, and G. Dubé: TMS Light Metals, TMS-AIME, New York, 1985, pp. 1179-95.

23. C.J. Simensen and G. Berg: Aluminium, 1980, vol. 56, pp. 335-40.

24. M. Badowski and S. Instone: TMS Light Metals, Wiley, Hoboken, 2012, pp. 1077-83.

25. M. Gökelma, P. Le Brun, T. Dang, M. Badowski, J. Morscheiser, B. Friedrich, and S. Tewes: TMS Light Metals, Nashville, 2016, pp. 843-48.

26. J.F. Richardson and W.N. Zaki: Chem. Eng. Sci., 1954, vol. 3, pp. 65-73.

Publisher's Note Springer Nature remains neutral with regard to jurisdictional claims in published maps and institutional affiliations. 